\title{
Twin studies of psychosis and the genetics
}

\section{of cerebral asymmetry ${ }^{\dagger}$}

\author{
T. J. CROW
}

Kläning (1999, this issue) reports that dizygotic twins are at increased risk of schizophrenia relative to the general population. Any departure from the first assumption of twin studies that the illness has the same origin in twins as it does in the general population might tell us something about aetiology. Kläning's expectation that monozygotic twins would be at increased risk because such pairs are at increased risk of perinatal complications was not confirmed, adding to the weight of evidence that such complications are unrelated to the origins of psychotic illness. The contrary finding that dizygotic twins are at increased risk draws attention to the nature of dizygotic twinning. Is there something about this process that yields a clue to the origins of psychosis?

\section{TWINNING, CEREBRAL ASYMMETRY AND PSYCHOSIS}

In the light of Kläning's finding, I draw attention to an aspect of the twin literature that relates it to a new (or resuscitated) concept of the genetics of psychosis - that it is a sub-field of the genetics of cerebral asymmetry. I argue that the findings in twin studies are consistent with this proposition, and that the anomaly that Kläning has uncovered may provide the key to the nature of the relationship.

Twinning itself is familial. Boklage (1981) drew attention to a relationship between twinning and handedness. The parents of twins (in general not themselves twins) are much more likely than their non-twin-bearing siblings to be nonright-handed. Boklage (1977) also suggested that there is a relationship between handedness, twinning and schizophrenia, and reported that in 28 monozygotic twin pairs concordance for schizophrenia was

'See pp. 407-409, this issue. linked to concordance for right-handedness. If true, this would constitute rather compelling evidence that the genetics of handedness and predisposition to schizophrenia were linked. However, three subsequent studies (Luchins et al, 1980; Lewis et al, 1989; Torrey et al, 1993) of handedness in twins with schizophrenia have yielded discrepant findings. A reasonable consensus is that "handedness does not appear to be a useful measure for studying lateralisation in this disease" (Torrey et al, 1993). A possible explanation is that handedness reflects only indirectly how the brain has developed, and that it is not direction of asymmetry per se that is genetically determined but degree (or perhaps degree and direction) that is the key factor (Crow et al, 1998).

Morphological studies yield a more consistent picture. In a seminal but

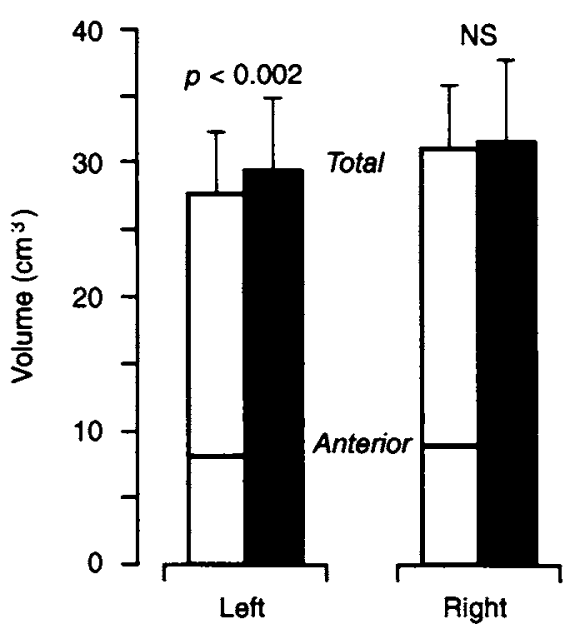

(a)

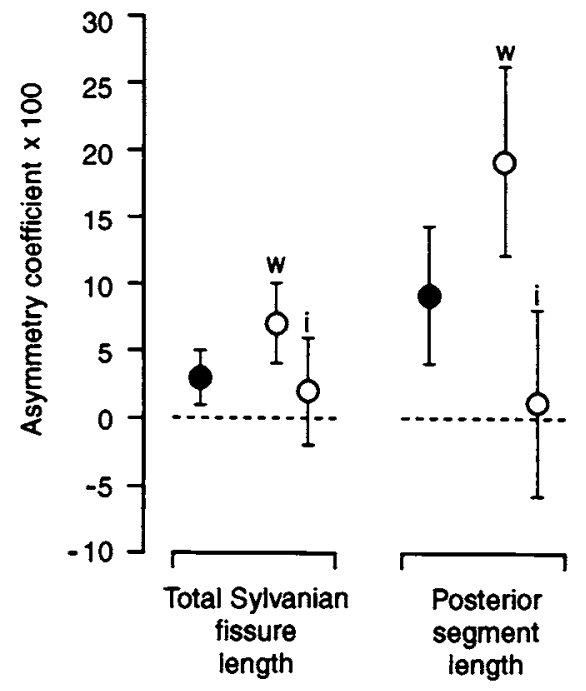

(b)

Fig. I Deviations in cerebral asymmetry in the National Institute of Mental Health discordant monozygotic twin study (bars represent standard errors). (a) Decrease in volume of grey matter in the posterior temporal bbe on the left side ( $\square$ ill twin; 1 well twin). The horizontal bar indicates grey matter volume in the anterior temporal lobe, which is unchanged (data from Suddath et ol, 1990). (b) Asymmetry coefficients (( $L-R)$ ) $(L+R) \times(00)$ of total and posterior Sytvian fissure lengths. $O$ values in discondant monozygotic pairs: $w$ - well twin, i - ill twin; values in control pairs of twins - both well (data from Bartley et ol, 1993). 
cortex that have developed in relation to language. This interpretation is supported by a re-analysis of measurements (Bartley et al, 1993) on the same twin series relating to the posterior extremity of the Sylvian fissure (Crow, 1995, Fig. 1(b)).

The findings in discordant monozygotic twins are therefore consistent with a literature (Crow, 1990, 1997; Petty, 1999) that suggests that the key anatomical change in schizophrenia is a loss or even a reversal (Highley et al, 1998) of asymmetry. One reason why this may not have been apparent earlier is that the asymmetry of the human brain is subtle; even though it may be accounted for by a single gene, its expression in cortical structure is complex, comprising an antero-posterior 'torque' from right frontal to left occipital.

The hypothesis that the genetics of psychosis is indeed linked to asymmetry is supported by the observations that not only is mixed handedness (a measure of degree rather than direction) increased in a cohort of patients with schizophrenia, but that there is also an increase in their first-degree relatives (Orr et al, 1999), and that loss of anatomical asymmetry is present in both affected individuals and 'obligate carriers' - relatives intermediate between two affected family members (Sharma et al, 1999).

\section{EPIGENETICS AND GENDER DIFFERENCES}

There have been three recent attempts (Annett, 1999; Klar, 1999; Yeo et al, 1999) to apply theories of asymmetry to psychosis. However, the genetics of cerebral asymmetry are themselves obscure (see for example Corballis, 1997) - no locus for asymmetry has been identified. This is also true for psychosis - the findings of genomic scans for linkage to psychosis are fraught with inconsistency (Crow \& DeLisi, 1998), and the reasons for this failure are unclear. One possibility is that predisposition to psychosis is not genetic in the sense that it is associated with DNA sequence variation but 'epigenetic' - that is, it relates to gene expression regulated by a process such as methylation that is associated with 'imprinting' or X chromosome inactivation.

Kläning's (1999, this issue) main finding is relevant to this possibility, and takes on a new aspect in the context of the gender difference that she also reports. Dizygotic twinning but not monozygotic twinning

T. J. CROW, FRCPsych, Department of Psychiatry, Warneford Hospital, Oxford OX3 7]X. Tel: 01865226474 ; Fax: 01865244990

(First received 23 April 1999, accepted 28 April 1999)

increases with parental age (Bønnelykke, 1990), as does the incidence of schizophrenia. Activation of genes on the inactivated $X$ chromosome increases with age (Wareham et al, 1987). Could these phenomena be related? Could they for example reflect an influence of $X$ chromosome inactivation or imprinting on predisposition to psychosis and dizygotic twinning?

The earlier onset of schizophrenia in males is unexplained, as are gender differences in handedness and verbal ability females are more lateralised or lateralise earlier and have greater verbal fluency than males. One explanation is that the gene for cerebral asymmetry is in the $\mathrm{X}-\mathrm{Y}$ homologous class, that is, represented on both $X$ and $Y$ chromosomes (Crow et al, 1998; Crow, 1999), but is expressed to a different degree in either case. If this gene is a determinant of relative rates of hemispheric growth it could explain the changes in schizophrenia including a relationship to gender (Highley et al, 1998) as well as, perhaps, earlier onset of psychosis and increased susceptibility to dyslexia in males.

Kläning finds that the increase in liability to schizophrenia that she has uncovered in dizygotic twins is greater in females. Possibly this gender difference is unrelated to the others that have to be explained. Maybe those for cerebral asymmetry are unrelated to the age of onset difference in psychosis. However, given the apparent failure of the linkage strategy as a hypothesis-free route to the discovery of genes for psychotic illness, it may be necessary to reconsider everything that we think we know about the nature of the genetic predisposition to the condition. Kläning's study contributes a hitherto unexpected ingredient.

\section{REFERENCES}

Annett, M. (1999) The theory of an agnosic right shift gene in schizophrenia and autism. Schizophrenio Research, 39, 177-182.

Bartley, A. J., Jones, D K., Torrey, E. F., et at (I993) Sylvian fissure asymmetries in monozygotic twins: a test of later ality in schizophrenia. Biologicol Psychiouty, 34. 853-863.

Boldase, C. E. (1977) Schizophrenia, brain asymmetry development and twinning: cellular relationships with etiological and possibly prognostic implications. Biological Psychiotry, 12, 19-35

- (19a1) On the distribution of non-right handedness among twins and their families. Acta Geneticoe Medicae Gemellologicae, 30, 167-187.

Bonnelyklos, B. (1990) Maternal age and parity as predictors of human twinning. Acta Geneticae Medicae Gemellologicoe, 39. 329-334.

Corballs, M. C. (19M7) The genetics and evolution of handedness. Psychological Review. 104. 714-727.

Crow, T. J. (1990) Temporal lobe asymmetries as the key to the etiology of schizophrenia. Schizophrenio Bulletin, 16, 433-443.

- (1995) The relationship between morphologic and genetic findings in schizophrenia: an evolutionary perspective. In Schizophrenio: An Integrated View. Alfred Benzon Symposium 38 (eds R. Fog \& J. Gerlach). pp. 15-25. Copenhagen: Munksgaard.

- (1997) Schizophrenia as failure of hemispheric dominance for language. Trends in Neurosciences, 20. 339-343.

- (I999) Commentary on Annett, Yeo et al. Klar, Saugstad and Orr: Cerebral asymmetry. language and psychosis - the case for a homo-sapiens-specific sexlinked gene for brain growth. Schizophrenio Research, 39. 219-231.

—, Crom, L R., Done, D. J., et of (1990) Relative hand skill predicts academic ability: global deficits at the point of hemispheric indecision. Neuropsychologia. 36. 1275-1282.

- DeLis, L. E (1998) The chromosome workshops at the Sth International Congress of Psychiatric Genetics: the weight of the evidence from genome scans. Pychiatric Genetics, 8, 59-6I.

—, Fith, C. D. Johnatone, E C., et al (1991) Crow's lateralization hypothesis for schizophrenia. Archives of Generol Psychiotry, 48, 86-87.

Htshloy, J. R., Esirl, M. M., Cortina-Borja, M., a d (1990) Anomalies of cerebral asymmetry in schizophrenia interact with gender and age of onset: a post mortem study. Schizophrenia Reseorch, 34, 13-25.

Ktining, U. (1999, this bawe) Increased incidence of schizophrenia in dizygotic twins. but not in monazygotic twins. British fournal of Psychiatry, 175, 407-409.

Ktar, A. J. S. (19\%9) Genetic models for handedness, brain lateralization. schizophrenia and manicdepression. Schizophrenio Research, 39, 207-218.

Lowts, S. W, Chitdara, B. \& Reveley, A. M. (Ises) Hand preference in psychotic twins. Biologicol Psychiatry. 25. 215-221.

Luchins, D J., Pollin, W \& Wratt, R. J. (19e0) Laterality in monozygotic twins: an alternative hypothesis. Biological Asychiotry, 15, 87-93.

Orr, K., Cannon, M., Eltvarry, C., ex of (1999) Schizophrenic patients and their first degree relatives show an excess of mixed handedness. Schizophrenia Reseorch. 39, 167-176. 
Potty, R. G. (I999) Structural asymmetries of the human brain and their disturbance in schizophrenia. Schizophrenia Bulletin, 25, 121-139.

Reveley, M. A., Reveley, A. M. \& Baldy, R. (1987) Left hemisphere hypodensity in discordant schizophrenic twins: a controlled study. Archives of General Psychiatry, 44, 625632

Sharma, T. M., Lancaster, E., Simindsson, T., et al (1999) Lack of cerebral asymmetry in familial

schizophrenic patients and their relatives: confirmation of Crow's hypothesis. Schizophrenia Research, in press.

Suddath, R. I., Christison, G.W., Torrey, E. F., et al (1990) Anatomical abnormalities in the brains of monozygotic twins discordant for schizophrenia. New England journal of Medicine, 322, 789-794.

Torrey, E. F., Ragiand, J. D., Gold, J. M., of af (1993) Handedness in twins with schizophrenia: was Boklage correct? Schizophrenia Research, 9. 83-85.
Wareham, K. A., Lyon, M. F., Glenister, P. H., et al (I987) Age related reactivation of an $X$-linked gene. Noture, 327, 725-727.

Weinberger, D. R., Suddath, R. C., Casanova, M. F., ot al (1991) Crow's "Lateralisation hypothesis for schizophrenia". Archives of Generol Psychiotry, 48, 85.

Yeo, R. A., Gangestad, S. W., Edgar, C., et ol (1999) The evolutionary-genetic underpinnings of schizophrenia: the developmental instability model. Schizophrenia Reseorch, 39, 197-206. 